\title{
A fenomenologia revelada: Georges Bataille e a alteração da sociologia*
}

\section{RESUMO}

Nesse artigo propomos refletir sobre à fenomenologia batailleana propriamente dita, ou seja, trabalhar na sua distinção da sociologia convencional ou ortodoxa. O objetivo é contribuir na construção de uma história das ideias sociológicas que permitam, pela obra de Georges Bataille, preencher algumas das lacunas de definição derivadas da ciência durkheimiana.

\section{PALAVRAS-ChAVE}

Fenomenologia

Sociologia compreensiva

Georges Bataille

Phenomenology revealed: Georges Bataille and the change in sociology

\section{ABSTRACT}

In this paper we propose to reflect about the phenomenology batailleana itself or, in other words, working on his distaining conventional or orthodox sociology. The objective is work the construction of a sociological history of ideas that allow the work of Georges Bataille to fill some gaps in the definition derived from the Durkheimian science.

\section{KEYWORDS}

Phenomenology

Comprehensive Sociology

Georges Bataille

\section{Philippe Joron}

Professor de Sociologia na Université Paul-Valéry - Montpellier III e pesquisador do IRSA-CRI/FR

philippe.joron@univ-montp3.fr
Em meus trabalhos precedentes sobre La vie improductive e ${ }^{2}$ a fête à pleins bords ${ }^{3}$ não deixei de evocar minha afiliação franca e sem complexo à sociologia compreensiva, consumida na exploração do cotidiano e do imaginário como perspectivas ou alavancas de pesquisa. Fiz igualmente referência à fenomenologia social quando abordei as questões da telerrealidade da violência no Brasil $^{4}$ e da alterologia comunicacional ${ }^{5}$. $\mathrm{Na}$ continuação destes estudos, que não foram afinal mais do que uma interpretação expandida de alguns pontos específicos da obra de Georges Bataille na análise de objetos de aplicação particulares, minha atenção se volta a fenomenologia batailleana propriamente dita ou, o que quer dizer sensivelmente o mesmo, sobre sua distinção da sociologia convencional ou ortodoxa: uma história das ideias sociológicas que situa a obra de Georges Bataille na eliminação das lacunas de definição aplicadas à ciência durkheimiana. Bataille sociólogo? Bataille fenomenólogo? Tudo isso sem dúvida, e bem mais, relacionado a estas duas primeiras denominações, o que permitiu que Jean Duvignaud convocasse solenemente e com uma certa coragem o autor de $A$ parte maldita em sua Anthologie des sociologues français contemporains6. Desta feita,

\section{eu reforno à fonte de meu questionamento sobre o laço social e a forma de considerá- lo, tentando afualizar uma sociologia da consumação, aplicada aos objetos que ela privilegia, mas também à seus próprios processos de conhecimento, tal como o vislumbrava Georges Bataille:}

ancoragens e perspectivas ou, se preferirmos, memória prospectiva que, doravante, dá ênfase à fenomenologia social em seus fundamentos e, mais uma 
vez, nas interpretações que lhe constituem.

Nossa maneira de conceber as coisas e o mundo, transmitida de uma geração à outra e também difundida entre as culturas, é o produto de um processo de socialização ou de enculturação que se traduz em termos de ensino, de reprodução e de inovação. $\mathrm{Na}$ realidade, nós apreendemos e compreendemos o mundo com os instrumentos rudimentares que nos foram colocados à disposição por herança.

A fenomenologia propõe questionar essas noções sem para tanto impor sua concepção como nãodefinitivas. É, então, do ponto de vista da socialização e da transmissão de conhecimentos, entre outras perspectivas privilegiadas, que a sociologia pode empreender uma abordagem fenomenológica do social. Se a fenomenologia detém uma significação para os sociólogos é sobretudo porque ela permite - ao menos é a ambição do pressuposto teórico de Edmund Husserl - questionar nossa cultura, nossos modos de apreensão e de ser no mundo. Colocar em questão uma cultura não significa rejeitá-la ou abolí-la, mas sim colocá-la em suspenso, ou em reserva.

Edmund Husserl preconizava um retorno às coisas?. Em sua utilização, adaptação ou adoção sociológica, o trabalho fenomenológico consistirá então em suspender as noções das quais dispomos para evoluir no mundo da compreensão, a fim de elucidar o estatuto das coisas tais quais elas são na realidade, sem passar pelo filtro da nossa cultura (linguagem, estruturas simbólicas, [...]). Para Husserl, de fato, perceber a maneira como as coisas aparecem diretamente equivale à perceber sua realidade.

De um ponto de vista genético, ou seja, histórico, a fenomenologia husserliana está estreitamente ligada à sociologia compreensiva tal como foi circunscrita por Max Weber. Há assim uma relação íntima entre "o retorno às coisas em elas mesmas" e a significação weberiana da sociologia: uma ciência que tenta compreender interpretativamente o sentido das ações e explicá-las causalmente em suas trajetórias e seus efeitos ${ }^{8}$. Mas esta relação íntima não consegue separar as diferenças de importância entre as exigências de cada uma dessas sensibilidades teóricas. Primeiramente, convém perceber que a segunda parte da sociologia weberiana - ou seja, a explicação causal - não tem lugar na fenomenologia. Em seguida, e como consequência do primeiro problema, existe uma certa tendência da fenomenologia de não levar em conta a história ou o tempo cronológico, ou ainda o diacrônico na compreensão dos fatos.

O conceito de intencionalidade comporta, contudo, uma perspectiva sociológica incontestável. Este conceito, objeto de modificações subsequentes, foi pego emprestado por Husserl da obra de seu professor Franz Brentano (1838-1917), filósofo e psicólogo austríaco. De maneira esquemática, podemos dizer que

\section{a infencionalidade significa uma inexistência de consciência, exceto a consciência de alguma coisa, ou seja, uma consciência necessariamente relacionada aos objetos dos quais ela se nutre, uma consciência cuja existência se deve à correlação entre estes mesmos objetos e as ações sugeridas por sua presença.}

Este conceito permitirá, principalmente, reunir posições filosóficas e sociológicas por vezes contraditórias em uma sensibilidade que pode ser qualificada de humanista e culturalista: encontramos aqui os detentores de uma sociologia existencialista como Husserl, claro, mas também Weber, Schutz, Sartre, Merleau-Ponty, Heidegger, Scheler; aqueles da sociologia do conhecimento, como Mannheim ou Berger e Luckmann; aqueles ainda de uma sociologia marxista, como Sartre ou Marcuse; e também representantes do interacionismo simbólico, como Mead ou Goffman e da etnometodologia, como Garfinkel. A sensibilidade na qual eles se reconhecem se opõe de todas as formas a uma abordagem positivista-naturalista do mundo e do social.

A influência da fenomenologia nas ciências sociais pode desde então se medir pelo seguinte constato: os seres humanos não agem e não pensam somente em função dos fatos e das forças sociais; eles formulam, modelam, constroem seus próprios universos graças aos sonhos e esperanças, os quais interagem com os seres da natureza. Convém então encontrar, em função destas características originais, métodos específicos capazes 
de tornar operantes o estudo e a compreensão destes processos tipicamente humanos.

O objeto das ciências sociais é, então, o estudo do mundo-vida, ou seja, a ecologia da vida social, analisando principalmente seus processos de constituição. Para Edmund Husserl e seu discípulo Alfred Schutz, esta análise é centrada sobre os fenômenos de consciência, o que vela um pouco tudo o que se refere à vida material. Entretanto, esta posição não será partilhada por Jürgen Habermas, o qual considera que a consciência não pode ser separada das circunstâncias materiais que lhe servem de matriz.

A interrelação entre fenomenologia e ciências sociais se estrutura, assim, pela execução de três grandes projetos. Primeiro, o campo que consiste em neutralizar a divisão cartesiana entre o espírito e o corpo, mais exatamente entre o significado e o ser, mais ainda entre o pensamento e seus objetos. Em seguida, a edificação das ciências sociais no seio das quais a fenomenologia se distinguiria como ciência metasocial. Se as ciências sociais são empíricas, a fenomenologia transcedental é igualmente, na medida em que seu primeiro postulado, aquele da possibilidade de uma intuição absoluta e incondicional das essências, é reconhecido por Husserl como um fato da experiência radical. Deste ponto de vista, o empirismo não é limitado à percepção dos sentidos mas, ao contrário, se abre às atividades de consciência: o pensamento é experiência. Enfim, a elaboração de uma fenomenologia das ciências sociais, que consiste no estudo dos processos pelos quais passamos das tipificações mundanas, das formulações do homem em sua vida cotidiana (formulações de primeira ordem segundo Schutz) às tipificações científicas (idealizações, abstrações, construções de segunda ordem segundo Schutz).

Entre outras abordagens possíveis, a fenomenologia pode ser compreendida como uma intelectualização do homem no que concerne as prerrogativas deste último frente ao mundo e a ele mesmo, alguns diriam uma meditação sobre suas maneiras de conhecer o mundo assim como sobre as próprias funções do conhecer.

A respeito da fenomenologia husserliana, falaremos de colocar entre parênteses os saberes culturais, uma maneira de expulsar os bens culturais, de separá-los, de praticar a a-historicidade, de ir ao limite do saber para encontrar, talvez, o que Georges Bataille denominava o não-saber radical. Há aqui uma posição crítica quanto ao que a ciência supõe, uma vez que se tratará de recusar o modelo da explicação para entrar a fundo na descrição das vivências. Mas este "fora" da ciência será, a princípio, praticado somente para reinvestir nas condições de existência da ciência, como foi feito por Kant, a respeito do conhecimento.

Esta problemática é de grande interesse para

\section{as ciências humanas que, frequentemente, posicionam 0 social, o humano, como objefo de dissecação para tentar, custe o que custar, digerí-lo, fagocifá-lo, incorporá-lo ao sujeito conhecedor.}

Utilizando os métodos objetivos, experimentais das ciências da natureza, as ciências humanas estabelecem uma consciência que se apropria do mundo exterior, enquanto que o método fenomenológico desfaz este primeiro movimento e instaura uma consciência que se manifesta neste mesmo mundo, que ali se dispersa, que tem como foco não mais a apropriação, e sim a relação com o objeto.

A fenomenologia constrói assim uma problemática da correlação que estabelece uma relação recíproca entre o pensamento e seu objeto. Esta problemática faz, logicamente, aparecer a questão essencial da subjetividade que não poderia ser suspensa, nem mesmo eliminada de uma vez por todas. De fato, se a consciência é sempre consciência de alguma coisa (Brentano), ela se define então como intencionalidade. O que volta ao fato de que todo objeto (coisa, conceito, etc.) é objeto para uma consciência. Em matéria de ciência, é então essencial para Husserl descrever a maneira como os atores adquirem consciência do objeto, seus processos de conhecimento quanto a este objeto, suas maneiras de considerá-lo como objeto.

No domínio das ciências humanas, a fenomenologia discute um certo número de problemas práticos que já eram objetos de debate na filosofia: a relação sujeito/ objeto, a dualidade idealismo/realismo, a confrontação entre objetividade e subjetividade.

Toda antropologia sociológica postula a inteligibilidade do homem pelo homem, o que posiciona de maneira original a relação entre o observador e o fato observado, impregnado de humanidade. Jean-François 
Lyotard, em seu estudo sobre a fenomenologia, nela vê a expressão de uma "socialidade originária", ou seja, uma "relação através da qual os sujeitos são determinados uns aos outros" ?. Já Maurice Merleau-Ponty, em sua Phénoménologie de la perception ${ }^{10}$, compreendia o social como determinado antes que se aplicasse sobre ele nossos atos de consciência: este mundo determinado sendo nada menos do que aquele da intersubjetividade. $\mathrm{O}$ outro não é como um objeto para mim, separado das minhas vivências e da minha intencionalidade, ele é sobretudo um ego, um outro eu mesmo, capaz de experimentar sua própria vivência. Haveria, então, uma espécie de coexistência do eu e do outro no seio da qual se elabora o sentido do social.

Do ponto de vista da análise merleau-pontyana, esta relação intersubjetiva é baseada no transitivismo, ou seja, uma história feita de condutas em rede e de intencionalidades interconectadas. Isso nos leva a compreender o social a partir do substrato original que ele representa para cada um de nós, e também para o sociólogo. Em outros termos,

\section{o social não pode ser definido exclusivamente como objefo. E se ele é objeto de pensamento para a sociologia, é este próprio pensamento que se torna objeto de especulação. Se existe o social em mim, se eu significo \\ o social com os outros, este social é para mim enfão um objeto poroso, permeável, assim como eu mesmo.}

Quer dizer que toda sociologia é fundada sobre um certo psicologismo?

Este é ao menos o qualificativo que alguns atribuíram à posição de Jules Monnerot quando este se propôs a contrariar aquele de Emile Durkheim. Para Monnerot, a sociedade não existe, só existem relações interindividuais: os fatos sociais não se reduzem a condutas ou comportamentos individuais. $\mathrm{O}$ fato social não pode ser considerado como uma coisa na medida em que ele não está situado somente de fora do observador social, mas também dentro dele, em seus fundamentos de existência. A sociedade começa na emergência da alteridade. Se "os fatos sociais não são coisas" como sustenta Jules Monnerot, é porque eles são vitais, desprovidos de inércia, cheios de experiências que interpelam aquelas do observador. Jean-Paul Sartre, em sua crítica ao marxismo contemporâneo, fechado na frieza de sua retórica científica e de sua incompreensão a respeito das realidades humanas, evocava esta mesma pretensão do positivismo sociológico: "A mistificação suprema do positivismo é que ele pretende abordar a experiência social sem a priori, enquanto que ele decidiu a princípio negar uma de suas estruturas fundamentais e substituí-la por seu oposto. Era legítimo que as ciências da natureza se redimissem do antropomorfismo que consiste em emprestar aos objetos inanimados propriedades humanas. Mas é perfeitamente absurdo introduzir por analogia o menosprezo do antropomorfismo na antropologia".

Em La pensée et le Mouvant"1 Henri Bergson já fazia referência em 1934 às teorias do conhecimento, sendo a principal aquela desenvolvida por Edmund Husserl, que celebrava um retorno à imediatidade determinada. Este retorno à imediatidade determinada fazia, aliás, eco com o retorno prévio aos trabalhos de Bergson sobre Les données immédiates de la conscience (1889), que tendiam a aproximar bem mais do que a distinguir Realismo e Idealismo $^{12}$. Pois existe no intuicionismo de Bergson uma perspectiva realista que encontramos, por exemplo, no centro de seu estudo sobre Matière et Mémoire (1896): as imagens são, assim, confundidas com a realidade ${ }^{13}$. Da mesma forma, a percepção pura coloca cada um de nós nas coisas. É por ela que as qualidades da matéria são conhecidas em si, a partir de dentro. É por esta razão que segundo Bergson a matéria é absolutamente como ela parece ser. Em sua Introduction à la Métaphysique, inicialmente publicada na Revue de métaphysique et de morale em 1903 e reprisada em seguida em Lapensée et le mowvant, ele reitera a imediatidade determinada da realidade exterior sobre o espírito, afirmando que "o senso comum tem razão sobre esse ponto contra o idealismo e o realismo dos filósofos".

Assim, o real se resume em Bergson a um mundo de imagens. Deste ponto de vista ele defende um certo idealismo já que ele percebe um parentesco ou uma 
analogia entre realismo e consciência. Mas este mesmo idealismo é, contudo, limitado por sua incapacidade de unir os fenômenos naturais entre eles. Da mesma forma, o realismo, em seus fundamentos estritos, não consegue explicar a maneira como a realidade se reproduz no espírito sob a forma de imagens. Bergson pretende então se situar além do realismo e do idealismo, no profundo de sua convergência.

Esta última posição acarreta remanejamentos especulativos quanto às relações sujeito/objeto, espírito/ matéria, mas também no que tange à própria ideia de objetividade sobre a qual é edificada a ciência. Conforme salientava Husserl, não existe realidade absoluta, mesmo que as essências sejam realidades inteligíveis que não podem ser produto do pensamento. Entretanto, toda realidade existe por doação e doação de sentido, porque ela se constitui na consciência: "tudo que pode ser e se chamar mundo e realidade deve ser representado no contexto da consciência real e possível". A objetividade da ciência, afinal, é a representação em vista de uma ação, uma soma de convenções encarregadas de encontrar o melhor modo de modificar os fenômenos.

Toda sociologia fenomenológica de Georges Bataille se apóia sobre estas mesmas convicções fenomenológicas. De maneira bem esquemática, é possível compreendê-la como uma sociologia do vivido, da imediatidade: uma sociologia do lado de dentro e da implicação. O que está em jogo aqui não é tanto o fato de entender o objeto e sim de reconhecer suas qualidades de entendimento: um objeto mais compreensível do que compreendido. Esta problemática está no centro de seu estudo sobre La souveraineté, ela mesma confrontada com o seguinte dilema: "A operação que é o conhecimento cessa a partir do momento em que a soberania é seu objeto" ${ }^{14}$. Quando de sua conferência em 5 de fevereiro de 1938, no Colégio de Sociologia Sagrada, ele sugere que esta soberania é como o próprio centro da existência do homem, que nada seria mais importante para este último "do que reconhecer-se dedicado, ligado ao que mais the aterroriza, ao que provoca seu maior desgosto" ${ }^{\prime 15}$. Georges Bataille convoca então o método fenomenológico, e também a psicanálise, como reforços da ciência sociológica para dar conta do sentimento de repulsa, de recalque em que implicam as coisas sagradas. Encontramos esta mesma preocupação em sua análise da estrutura psicológica do facismo publicado no $\mathrm{n}^{\circ} .10$ de la critique sociale em novembro de 1933, no qual ele discute as relações que a ciência mantém com o homogêneo e o heterogêneo, fazendo ainda algumas incursões na fenomenologia e na psicanálise para liberar o terreno minado de uma possível heterologia. O projeto é ambicioso: "constituir um conhecimento da diferença não explicável a qual supõe $\mathrm{o}$ acesso imediato da inteligência a uma matéria prévia à redução intelectual" ${ }^{16}$.

Enquanto Bergson, como vimos, indicava em La Pensée et le Mouvant o desenvolvimento de teorias do conhecimento da obediência fenomenológica, Raymond Aron publicava em 1935 seu primeiro livro, um estudo sobre $\mathrm{La}$ sociologie allemande contemporaine17 no qual ele familiarizava o leitor francês com a abordagem fenomenológica. Georges Bataille teve acesso a isto, assim como Jules Monnerot, Roger Caillois e Gaston Bachelard, que apresentaram esta sociologia fenomenológica na revista Inquisition no ano seguinte, de acordo com termos desprovidos de qualquer ambiguidade: a originalidade da ciência social alemã consiste, segundo eles, em tentar entender a partir do interior o fato social, em sua imediatidade, sua totalidade e sua essência, contrariamente às tentativas de objetivação incitados pela Escola Francesa de Sociologia da qual os cidadãos se puseram facilmente a erigir em dogmas "ilusões um pouco ingênuas de objetividade"

Dez anos mais tarde, em 1946, Jules Monnerot definirá a sociologia como uma psicologia humana que não será mais exclusivamente focada nos limites individuais. Ela só tem sentido, para ele, se ela se funde com a atitude fenomenológica, adotando a descrição como modo de ação e a vivência como único ponto de análise: "uma fenomenologia regional se referindo à descrição de uma vivência social" ${ }^{19}$.

\section{Se os fatos não são coisas, é porque eles não podem ser, antes de fudo, considerados como objetos puros: 0 pensamento sociológico não é pura confemplação de um em- si que lhe seria fotalmente estranho.}

Logo, nós vimos anteriormente que o realismo ao menos uma certa concepção do realismo ocorrente na sociologia - postulava a irredutibilidade do mundo 
exterior - e, assim, do social - em relação à consciência do sujeito: um mundo exterior que se impõe ao indivíduo como uma coisa ou um em-si. A fenomenologia social postulará, ao contrário, a dimensão vivida do mundo. Esta dimensão vivida é revelada em parte no senso comum, aquele contra o qual se edificou a ciência fabricando um outro acordo de intelectos, próprio às comunidades acadêmicas ocidentais. Mas, ao mesmo tempo, a fenomenologia social não corresponde a um idealismo puro ou absoluto. De fato, se o conhecimento é construção do inteligível, ou seja, adaptação do mundo exterior às normas da razão, ele é também uma descrição da vivência sem a qual ele não teria interpretação possível quanto ao sentido elaborado pelos indivíduos.

Esta concepção de sociologia, deliberadamente retirada de sua rigidez durkheimiana, marcará sensivelmente a visão de Georges Bataille quanto aos fatos sociais "sagrados". De acordo com o comentário de Jean-Michel Heimonet, "estes fatos têm em comum o escape à redução intelectual postulada por Durkheim; como tais eles constituem o inconsciente recalcado no qual se enraiza a organização econômica e política das sociedades industriais" ${ }^{20}$. Se realmente podemos falar de influência neste assunto, acordaremos em dizer que esta fenomenologia social constitui um reforço teórico das concepções bataillianas, uma justificação sociológica de sua atitude intelectual.

Estamos aqui em presença de uma sociologia em crise, a qual o estudo sobre "a estrutura psicológica do facismo” bem explica. A opção metodológica está ali, definitivamente: os estados descritos são necessariamente vividos, sabendo que "o método psicológico adotado exclui todo recurso à abstração" ${ }^{21}$. Mais uma vez, a sociologia não tem sentido a não ser que esteja enraizada na experiência e no engajamento moral. A implicação está, então, no centro da sociologia batailleana: é uma sociologia de combate. Como destaca Jean-Michel Heimonet: "a respeito desta afinidade entre a teoria e a prática, a impermeabilidade de princípio entre sociologia e psicologia que Durkheim reivindica parece invalidada pelo fundamento existencial de uma ciência onde o homem é, em um só, o objeto e o sujeito" ${ }^{22}$. Sem ir muito longe, encontramos aqui uma análise de Marcel Mauss a respeito "das relações reais e práticas da psicologia e da sociologia" 23 , que celebra não o englobamento de duas disciplinas sem delimitação precisa ou fixa, mas uma sinergia exploratória no estudo do homem completo.

Se para Jules Monnerot é absurdo querer tratar os fatos sociais como coisas, é primeiramente porque eles correspondem à "vivências". Como o explicará, mais tarde, Jean-Paul Sartre em suas Questions de méthode, "nossa compreensão do outro não é jamais contemplativa: é apenas um momento de nossa praxis, uma maneira de viver, na luta ou na convivência, a relação concreta e humana que nos une a ele" ${ }^{24}$. Na realidade, o objeto das ciências do homem e, logo, da sociologia detêm "modos próprios de se dar" que supõem, de volta ao observador, modos próprios de entendê-lo. Encontramos em Durkheim uma vontade de demarcar o objeto sociológico e de estabelecer um olhar específico que o apreenda como tal, com a firme intenção de constituir um domínio para a sociologia contra a psicologia. Segundo Monnerot, o erro de Durkheim consistiu justamente em diferenciar ao extremo os objetos destas ciências e em não ter insistido, ao contrário, na originalidade do princípio sociológico. Pois o objetivo da sociologia, sua motivação primeira, é também dar um novo sentido aos fatos ou fenômenos (aparição) que já são objetos de estudo de outras ciências: "o ponto de vista sociológico opera uma nova seleção sobre um dado já tratado por outras ciências" ${ }^{25}$. O que supõe uma constituição da sociologia não por exclusão, e sim pela contribuição de outras disciplinas.

A crítica de Jules Monnerot se porta em seguida sobre a delimitação dos métodos que, segundo Durkheim, garantem a originalidade do princípio sociológico. E, para Monnerot, o método preconizado é sempre tributário da natureza do objeto. Em outros termos, cada objeto remete a um método de abordagem particular, o qual se aproxima mais de seu desvelamento: "a natureza do objeto impõe a maneira como a abordamos" ${ }^{26}$.

Para Monnerot, a sociologia não é literalmente uma ciência, como pode ser a física com suas leis derivadas da soma das experimentações às quais ela se propõe. Ela não pode definir-se como uma ciência do homem dotada de um objeto específico como é o caso, por exemplo, da antropologia física, que mede as diferenças antropomórficas ou ainda a etnografia, que descreve os modos de ser das culturas não-históricas: "a sociologia é um ponto de vista sobre todas as ciências do homem ao mesmo tempo, que permite comparar seus elementos, fazer surgir a compreensão e a comparação destes elementos em um sentido novo" ${ }^{27}$.

Portanto, o que faz a especificidade da sociologia não é mais seu terreno objetivo, e sim o campo de visão que ela propõe para considerar objetos diversamente constituídos.

Da mesma forma, Jules Monnerot não reconhece nenhuma existência possível na sociedade enquanto 
corpo constituído: "existem estados de sociedade, estados sociais vividos pelos homens que situam e que datam as condições humanas" ${ }^{28}$. A suposta homogeneidade destas diversas vivências em um estado mais geral é apenas uma ilusão da apreciação que definiu Durkheim como um anti-pluralista.

Enfim, a sociologia deve ser considerada como um estado situado e datado: "não há observador sem posição e o observador é sua posição. Eu sou minha situação" Esta situação ou esta posição acarreta necessariamente uma visão, uma perspectiva que depende ela mesma de um conglomerado de valores mais ou menos condensado ou expandido. Valores que não poderiam ser negados pela sociologia: a apreensão do histórico e do social vivido por este último determina seu entendimento do histórico e do social não vivido por ele. Convém, então, segundo Jules Monnerot, assumir esta posição que já é fonte de conhecimento. Assim como a sociologia não pode separar a psicologia de seus raios de ação, pela natureza mesmo dos objetos que ela privilegia (todo fato social é, a princípio, um fato psicológico), a sociologia compreensiva não pode, em consequência disto, "dar folga à filosofia" ${ }^{30}$, porque ela é também a emissão de uma condição humana que reflete sobre ela mesma.

Se não pode existir uma só fenomenologia, regulamentar de alguma forma, mas sim diversas abordagens desta ordem aplicadas ao laço social e à situação do homem no mundo,

\section{nós encontramos naquela proposta de Georges Bafaille a tentativa de um conhecimento da diferença inexplicável, de um saber volfado às vivências da relação que fodo homem manfém com objetos ov sifuações de repulsão que fascinam e atraem.}

\section{NOTAS}

*Tradução de Roberta Coelho Barros - Doutoranda do Programa de Pós-Graduação em Comunicação da
PUCRS/RS/BR.

${ }^{2}$ JORON, Philippe. La vie improductive. Georges Bataille et l'hétérologie sociologique. Montpellier, Presses Universitaires de La Méditerranée, Coll. Sociologie des imaginaires, 2009. Prefácio de Patrick Tacussel. [Para edição em língua portuguesa : Porto Alegre, Editora Sulina, 2009].

${ }^{3}$ JORON, Philippe. La vie à pleins bords. Bayonne: fêtes de rien, soif d'absolu. Prefácio de Michel Maffesoli [no prelo]

${ }^{4}$ JORON, Philippe. Fenomenologia da televiolência. Revista FAMECOS, Porto Alegre, n.26, p. 49-59, 2004 ; JORON, Philippe. Phénoménologie de la télé-violence : normes hétérologiques du télé-journalisme policier brésilien. In: DOMINGO, Paola; VIGNAUX, Hélène (Org.). Arts et société en Amérique latine : la transgression dans tous ses états, Paris, Éd. L'Harmattan, Coll. Recherches Amériques latines. p. 139-153, 2009

5ORON, Philippe (Org.). França: midia e violência. Revista FAMECOS, Porto Alegre, n.29, 2006; JORON, Philippe. Violences et communication. Approches franco-brésiliennes des altérités communicationnelles. Les Cabiers de l'IRS A, Montpellier, Presses Universitaires de La Méditerranée, n. 6, 2006.

${ }^{6}$ DUVIGNAUD, Jean. Anthologie des sociologues français contemporains. Paris: PUF, p. 91-95, 1970.

${ }^{7}$ HUSSERL, Edmund. Idées directrices pour une phénoménologie. Paris, Éd. Gallimard, Coll. Tel, 1950. Trad. Paul Ricœur [1913 edição original].

${ }^{8}$ WEBER, Max. Economie et société. Paris, Éd. Plon, 1971 [Coll. Agora, 1995].

${ }^{9}$ LYOTARD, Jean-François. La phénoménologie. Paris, PUF, coll. Que-sais-je ?, p. 78, 1994. Ver também, HUNEMAN, Philippe; KULICH, Estelle. Introduction à la phénoménologie. Paris: Armand Colin, coll. Philosophie, 1997.

${ }^{10}$ MERLEAU-PONTY, Maurice. Phénoménologie de la perception. Paris: Éd. Gallimard, Coll. Tel, 1976.

${ }^{11}$ BERGSON, Henri. La pensée et le mouvant. Paris, PUF, Coll. Bibliothèque de philosophie contemporaine, 1966 
[1934].

${ }^{12}$ BERGSON, Henri. Essais sur les données immédiates de la conscience. Paris: PUF, Coll. Quadrige, 2001 [1889].

${ }^{13}$ BERGSON, Henri. Matière et mémoire. Paris: PUF, Coll. Quadrige, 1997 [1896].

${ }^{14}$ BATAILLE, Georges. La Souveraineté. CEuvres Complètes, Tome VIII, Paris: Éd. Gallimard, p. 253, 1976.

${ }^{15}$ BATAILLE, Georges. Collège de sociologie. CEuvres Complètes, Tome, II, Paris: Éd. Gallimard, p. 320, 1970.

${ }^{16}$ BATAILLE, Georges. La structure psychologique du fascisme. Euvres Complètes, Tome I, Paris, Éd. Gallimard, p. 345, 1970.

${ }^{17} \mathrm{ARON}$, Raymond. La sociologie allemande contemporaine, Paris, PUF, Coll. Quadrige, 1981 [Éd. Félix Alcan, 1935].

${ }^{18}$ Inquisition, n 1, juin 1936, p. 53-54. Em abril de 1939 é publicado na N.R.F. um relatório de Roger Caillois sobre a obra de S. A. Sorokin, Les théories sociologiques contemporaines. A revisão é extremamente crítica em relação à Sorokin, e encoraja o leitor a consultar os estudos de Raymond Aron sobre La sociologie allemande contemporaine e La sociologie de Pareto; LAMBERT, JeanClaude (Org.). Roger Caillois. Les Cahiers de Chronos, Paris, Éd. de la Différence, p. 76-77, 1991.
${ }^{19} \mathrm{MONNEROT}$, Jules. Les faits sociaux ne sontpas des choses. Paris, Ed. de Minuit, p. 62, 1946.

${ }^{20}$ HEIMONET, Jean-Michel. Pourquoi Bataille? Paris, Ed. Kimé, p. 14, 2000.

${ }^{21}$ BATAILLE, Georges. La structure psychologique du fascisme. Euvres Complètes, Tome I, p. 339, 1933.

${ }^{22}$ HEIMONET, Jean-Michel. Pourquoi Bataille? op. cit., p. 13, 2000.

${ }^{23}$ MAUSS, Marcel. Rapports réels et pratiques de la psychologie et de la sociologie (1924). Sociologie et Epistémologie, Paris, PUF, 2001 [1950].

${ }^{24}$ SARTRE, Jean Paul. Questions de méthode, op. cit., p. 141, 1980.

${ }^{25} \mathrm{MONNEROT}$, Jules. Les faits sociaux ne sont pas des choses. op. cit., p. 63, 1946.

${ }^{26}$ Ibidem, p. 64.

${ }^{27}$ Ibidem, p. 64.

${ }^{28}$ Ibidem, p. 75.

${ }^{29}$ Ibidem, p. 82.

${ }^{30}$ Ibidem, p. 86. 